\title{
Analysis on the Influence Factors of Directional Controlled Blasting Assisted by Water Jet
}

\author{
SU Dengfeng \\ School of Environment and Resource, Southwest University of Science and Technology, Mianyang 621010, China
}

\begin{abstract}
Directional expansion of blast-induced crack is always the common purpose for directional controlled blasting. As it has been demonstrated that slot which located at the side of blasthole can function as a guidance for blast energy, let the stress concentration at the direction of water jet slot. Therefore, it is meaningful to investigate the influence factors of directional controlled blasting with water jet assistance. In this paper, the influence on the guiding characteristics of the water jet slot during the propagation of blast-induced crack by the change of length-width of slot was simulated by ANSYS/LS-DYNA. The results indicate that if the distance from blasthole exceeds the limit, the influence on the guiding characteristics by the change length-width of the slot will get smaller and smaller, and when the width of water jet slot remains the same, the stress shows a monotonic increasing trend with the increase of the length of water jet slot, and the stress reaches its maximum value when the length-width of water jet slot is $0.075 \mathrm{~m} \times 0.0070 \mathrm{~m}$. Moreover, based on stress wave theory and rock fracture theory, the influential mechanism for both the law of transmission of stress wave and of crack propagation by natural fracture and water jet slot were analyzed. The criteria for blast-induced crack propagation were established.
\end{abstract}

Key words: Blast-induced crack, water jet slot, numerical simulation, influence factors.

\section{Introduction}

Directional controlled blasting technology is widely used in tunnel excavation and underground space engineering construction [1]. The best advantage of this kind of technology is the directional expansion of blast-induced crack [2, 3]. For this reason, many scholars have proposed and developed various directional controlled blasting technology [4-6]. In which, the directional controlled blasting technology with water jet assisted was proposed based on the unique properties of the water jet. The essence of this technology is the formation of stress concentration at the tip of the water jet slot during blasting, which plays a leading role in the propagation of blast-induced crack. For weak surrounding rock, protecting materials, such as plastic pipe and metal pipe was installing in the root of the blasthole, so the remained rock can be protected against damage during

Corresponding author: SU Dengfeng, Ph.D., lecturer, research fields: directional controlled blasting, mining engineering, water jet. blasting [7, 8], as shown in Fig. 1 b.

At the present, the guiding characteristics of the water jet slot during the propagation of the blast-induced crack have been demonstrated by many scholars $[9,10]$. Therefore, an attempt was made to investigate the influence law on the directional crack by the size of the water jet slot and the natural fracture, so as to promote the further development of this technology.

2. Simulation Study on the Influence Law of Guiding Characteristics by the Size of Water Jet Slot during the Propagation of Blast-induced Crack

\subsection{Numerical Simulation Model and Its Parameter}

Six simulation cases were conducted by ANSYS/LS-DYNA to understand the influence on the blast-induced crack propagation law by the size of the water jet slot. Due to the symmetry of the simulated object, both simulation cases applied a quasi-2-D simulation model. The parameters for each case are 


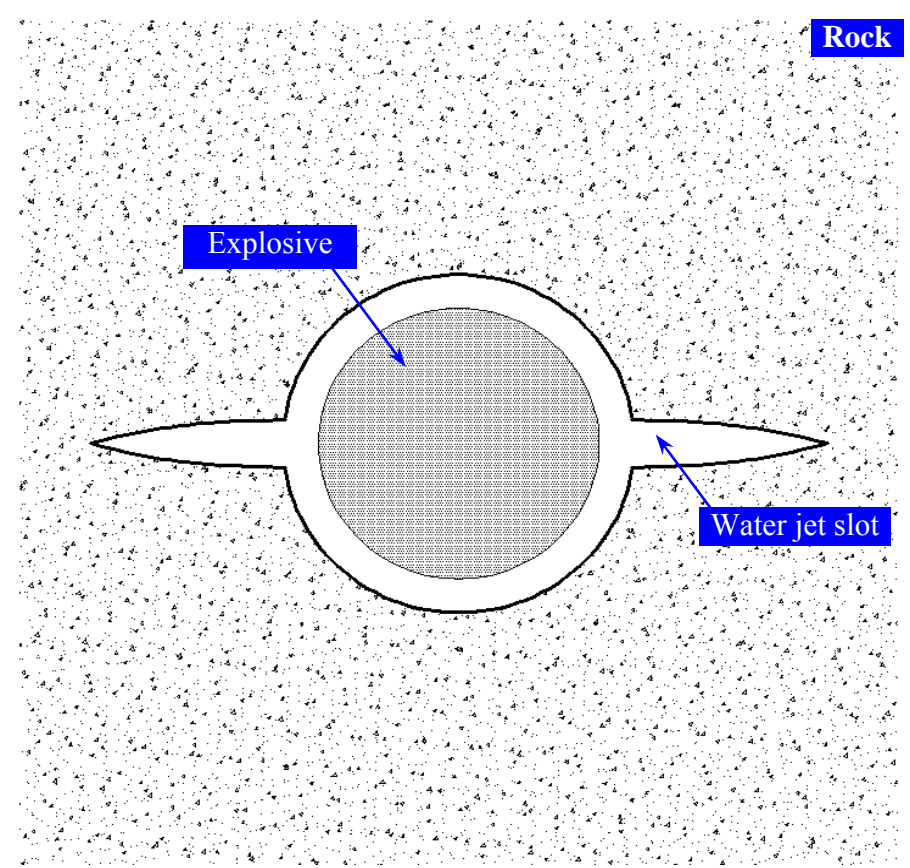

(a) Ordinary directional controlled blasting with water jet assisted

(b) Directional blasting with control blasting with blasthole protecting assisted by water jet

Fig. 1 Directional controlled blasting technology with water jet assisted.

shown in Table 4, and the simulation model of case 1 is shown in Fig. 2.

\subsection{Material Model}

\subsubsection{Explosive}

Material type 8 of LS-DYNA was chosen as the explosive model, and the pressure released by the chemical energy in the engineering calculations was modelled by the Jones-Wilkens-Lee equation of state. The JWL EOS can be written in the following form $[11,12]$.

$$
P_{\mathrm{e}}=A\left(1-\frac{\omega}{R_{1} V}\right) e^{-R_{1} V}+B\left(1-\frac{\omega}{R_{2} V}\right) e^{-R_{2} V}+\frac{\omega E_{\mathrm{e}}}{V}
$$




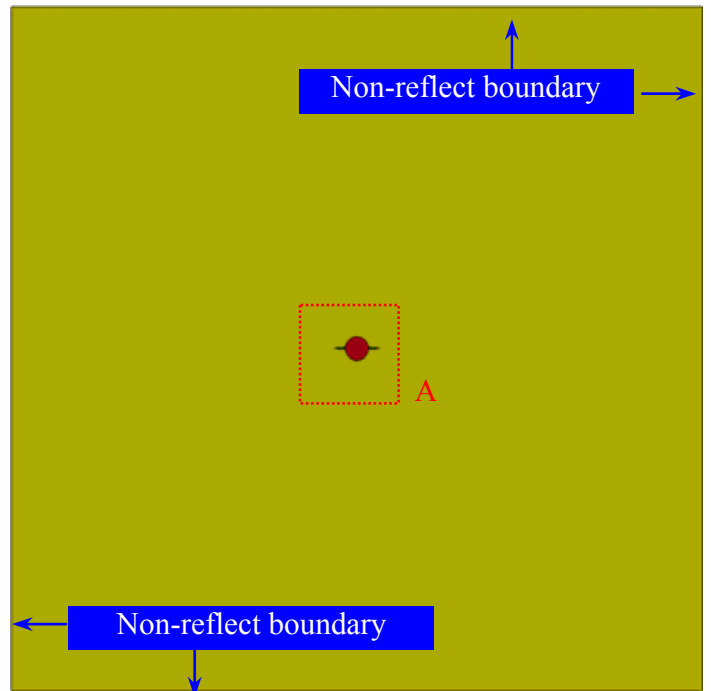

(a) Numerical simulation model

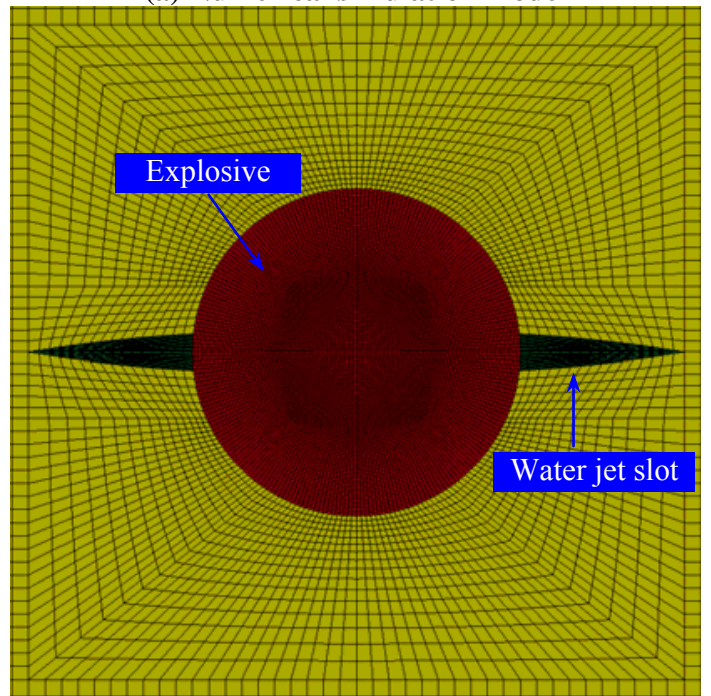

(b) Enlargement of part $\mathrm{A}$

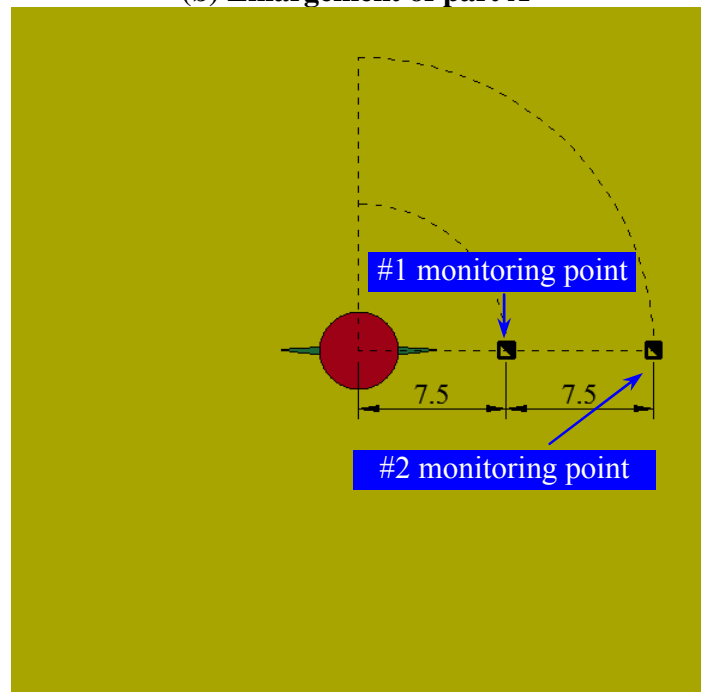

(c) Layout of monitoring points

Fig. 2 Numerical simulation model of Case 1. 
Table 1 Numerical simulation cases.

\begin{tabular}{llll}
\hline Case number & Size of rock $(\mathrm{m})$ & Diameter of blast hole $(\mathrm{m})$ & Length-width of water jet slot \\
\hline 1 & $1.5 \times 1.5 \times 0.003$ & 0.05 & $0.050 \times 0.0035$ \\
2 & $1.5 \times 1.5 \times 0.003$ & 0.05 & $0.050 \times 0.0070$ \\
3 & $1.5 \times 1.5 \times 0.003$ & 0.05 & $0.075 \times 0.0035$ \\
4 & $1.5 \times 1.5 \times 0.003$ & 0.05 & $0.075 \times 0.0070$ \\
5 & $1.5 \times 1.5 \times 0.003$ & 0.05 & $0.100 \times 0.0035$ \\
6 & $1.5 \times 1.5 \times 0.003$ & 0.05 & $0.100 \times 0.0070$ \\
\hline
\end{tabular}

Table 2 Parameters of explosive and its EOS equation.

\begin{tabular}{llll}
\hline$\rho_{e}\left(\mathrm{~kg} / \mathrm{m}^{3}\right)$ & $v_{D}(\mathrm{~m} / \mathrm{s})$ & $P_{\text {cut }}(\mathrm{MPa})$ & $A(\mathrm{MPa})$ \\
\hline $1.93 \times 10^{3}$ & $9.93 \times 10^{3}$ & $3.37 \times 10^{4}$ & $3.71 \times 10^{5}$ \\
$B(\mathrm{MPa})$ & $R_{1}$ & $R_{2}$ & $\omega$ \\
$7.43 \times 10^{3}$ & 4.15 & 0.95 & 0.30 \\
\hline
\end{tabular}

Table 3 Parameters of air and its EOS equation.

\begin{tabular}{lllll}
\hline$\rho_{a}\left(\mathrm{~kg} / \mathrm{m}^{3}\right)$ & $C_{0}$ & $C_{1}$ & $C_{2}$ & $C_{3}$ \\
\hline $1.25 \times 10^{3}$ & $-1 \times 10^{-6}$ & 0.00 & 0.00 & 0.00 \\
$C_{4}$ & $C_{5}$ & $C_{6}$ & $E_{a 0}$ & $V_{a 0}$ \\
0.40 & 0.40 & 0.00 & $2.5 \times 10^{-6}$ & 1.0 \\
\hline
\end{tabular}

Table 4 Parameters of rock.

\begin{tabular}{llllll}
\hline$\rho_{\mathrm{r}}\left(\mathrm{kg} / \mathrm{m}^{3}\right)$ & $E(\mathrm{MPa})$ & $P_{R}$ & $S I G T(\mathrm{MPa})$ & $\operatorname{ETAN}(\mathrm{MPa})$ & $F_{S}$ \\
\hline $2.55 \times 10^{3}$ & $2.25 \times 10^{4}$ & 0.22 & 3.24 & $4.25 \times 10^{3}$ & 0.06 \\
\hline
\end{tabular}

where $P_{\mathrm{e}}$ is the pressure produced by the detonation products from explosive, where $\omega, A, B, R_{1}$ and $R_{2}$ are user-defined input parameters, $V$ is the relative volume, and $E_{\mathrm{e}}$ is the internal energy per initial volume.

\subsubsection{Air}

Air was modelled by the material type 9 of LS-DYNA with the Gruneisen equation. The pressure $P_{a}$ can be calculated by Ref. [13].

$$
\left\{\begin{array}{l}
P_{a}=C_{0}+C_{1} \mu+C_{2} \mu^{2}+C_{3} \mu^{3}+\left(C_{4}+C_{5} \mu+C_{6} \mu^{2}\right) E_{a} \\
\mu=\frac{1}{V_{a}}-1
\end{array}\right.
$$

where $C_{0}, C_{1}, C_{2}, C_{3}, C_{4}, C_{5}$ and $C_{6}$ are user defined constants, $\rho_{a}$ is density of air, $V_{a}$ is the relative volume, $V_{a 0}$ is the initial relative volume of air, $E_{a}$ is internal energy, $E_{a 0}$ is the initial internal energy of air, as shown in Table 3.

\subsubsection{Rock}

Material type 3 of LS-DYNA was applied to model the rock [14], and its parameters were shown in Table 4.

\subsection{Algorithm}

To avoid the large deformation problem of explosive during the blasting process, fluid-solid coupling algorithm was adopted. In which, ALE algorithm is used for explosive and air filled in the water jet slot, Lagrange algorithm for rock. The governing equations of ALE algorithm can be expressed as follow $[11,15]$ :

$$
\begin{gathered}
\frac{\partial F\left(x_{i}, t\right)}{\partial t}=\frac{\partial F\left(y_{i}, t\right)}{\partial x_{i}}+w_{i} \frac{\partial F}{\partial x_{i}} \\
\frac{\partial \rho}{\partial t}=-\rho \frac{\partial v_{i}}{\partial x_{i}}-w_{i} \frac{\partial \rho}{\partial x_{i}} \\
v \frac{\partial v_{i}}{\partial t}=\sigma_{i j, j}+\rho b_{i}-\rho w_{i} \frac{\partial x_{i}}{\partial x_{\mathrm{j}}} \\
\rho \frac{\partial E}{\partial t}=\sigma_{i j} v_{i j}+\rho b_{i} v_{i}-\rho w_{j} \frac{\partial E}{\partial x_{j}}
\end{gathered}
$$


where $x_{\mathrm{i}}$ is Lagrangian coordinate system, $y_{\mathrm{i}}$ is Eulerian coordinate system, $w_{\mathrm{i}}$ is relative velocity, $\rho$ is the density, $v$ is the particle velocity, $E$ is Internal energy of unit mass, subscript $i$ and $j$ stand for the direction of coordinate. $\sigma_{i j}$ is Cauchy's stress tensor and can be expressed as the following equation:

$$
\sigma_{i j}=-p \delta_{i j}+\mu\left(v_{i, j}+v_{j, i}\right)
$$

where $\delta_{i j}$ is the Kronecker function.

On the other hand, according to the characteristics blasting process, the time step of the simulation is $0.67 \mu \mathrm{s}$, and the computation time is $0.0025 \mathrm{~s}$.

\subsection{Simulation Results Analysis}

Post-processing software (LS-PREPOST) was used to draw the stress time-history curves for each case, as shown below.

Figs. 3-6 show the radial stress history curve, tangential stress history curve, P-T history curve and effective stress history curve for each case respectively. By comparing these curves we can see that, for each curve of \#1 monitoring point, the stress time history curves show different changing law with the change of the length-width ratio. However, the stress time history curves of \#2 monitoring point show the same change law with the change of the length-width ratio. That is to say, the influence on the guiding characteristics by the change of the size of water jet slot during the propagation of blast-induce crack has its limit. If the distance from blasthole exceeds the limit, the influence on the guiding characteristics by the change of the size of water jet slot will get smaller and smaller.

Moreover, from each stress time-history curve for \#1 monitoring point we can see that when the width of water jet slot remains the same, the stress shows a monotonic increasing trend with the increase of the length of the water jet slot, and the stress reaches its maximum value when the length-width of water jet slot is $0.075 \mathrm{~m} \times 0.0070 \mathrm{~m}$.

\section{Analysis of the Influence Law on the Blast-induced Crack propagation by Natural Fracture}

\subsection{Transmission Law of Blast Stress Wave across Natural Fracture and Water Jet Slot}

Based on blasting theory $[14,16]$, huge stresses act on the wall of blast hole when explosive blast occurs, then the explosion stress wave forms and propagates in the rock. At the initial stage of blasting, P-wave is the mainly stress wave transmitted in the rock, therefore $\mathrm{P}$-wave is defined to be positive in the present study. According to stress wave theory [17], when the P-wave impinges on the interface of two media, both reflection and transmission take place, as shown in Fig. 7.

In which, $\alpha$ and $\beta$ are respectively the emergence angles of the incident $\mathrm{P}$-wave and the reflected S-wave. If the critical angles of the incident $\mathrm{P}$-wave are defined to be $\alpha_{\mathrm{c}}$, there is $0^{\circ} \leq \alpha_{\mathrm{c}} \leq 90^{\circ}$, when the incident angles are greater than the critical angles, the emergence angles of reflected and transmitted waves are no longer real-valued, which will not be discussed in the paper. According to the conservation of momentum on the wave fronts, there are

$$
\left\{\begin{array}{l}
\sigma_{\mathrm{ip}}=\rho_{\mathrm{r}} c_{\mathrm{p}} v_{\mathrm{ip}} \\
\sigma_{\mathrm{rp}}=\rho_{\mathrm{r}} c_{\mathrm{p}} v_{\mathrm{rp}} \\
\sigma_{\mathrm{tp}}=\rho_{\mathrm{r}} c_{\mathrm{p}} v_{\mathrm{tp}} \\
\tau_{\mathrm{rs}}=\rho_{\mathrm{r}} c_{\mathrm{s}} v_{\mathrm{rs}} \\
\tau_{\mathrm{ts}}=-\rho_{\mathrm{r}} c_{\mathrm{s}} v_{\mathrm{ts}}
\end{array}\right.
$$

where $v_{\text {ip }}, v_{\text {rp }}$ and $v_{\text {tp }}$ are the particle velocities of the incident, reflected and transmitted P-waves, respectively. $v_{\mathrm{rs}}$ and $v_{\mathrm{ts}}$ are the particle velocities of the reflected and transmitted S-waves, respectively, $\rho_{\mathrm{r}}$ is density of rock, $c_{\mathrm{p}}$ and $c_{\mathrm{S}}$ are, respectively, the $\mathrm{P}$ - and S-wave propagation speeds in the intact rock. According to Snell's law, the relationship between $\alpha$ and $\beta$ can be written as 


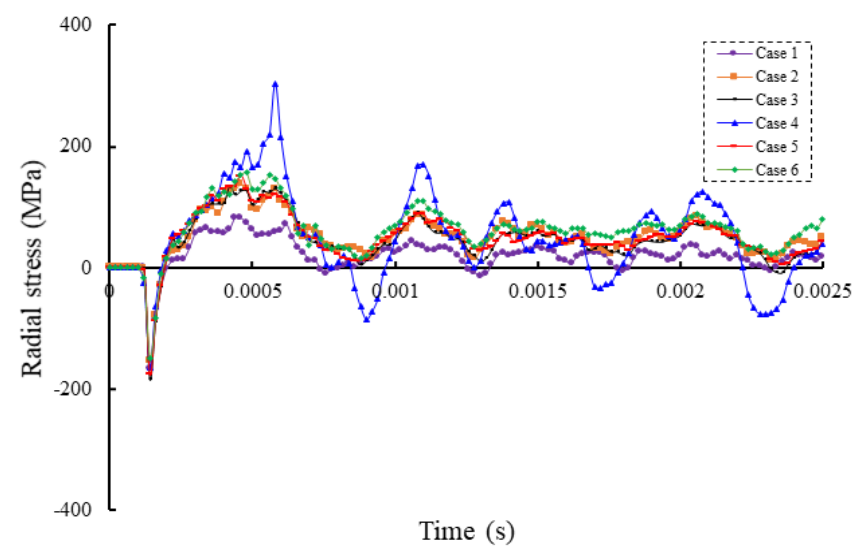

(a) \#1 monitoring point

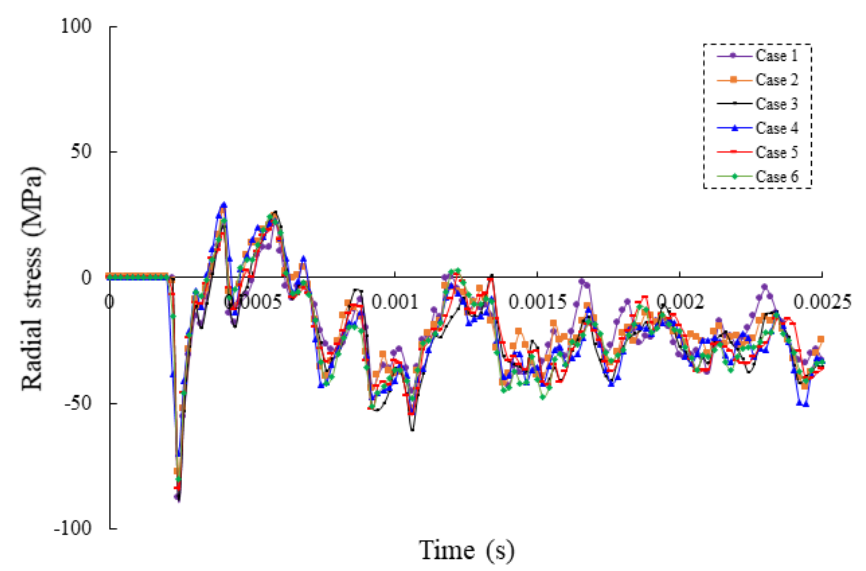

(b) \#2 monitoring point

Fig. 3 Radial stress history curve for each case.

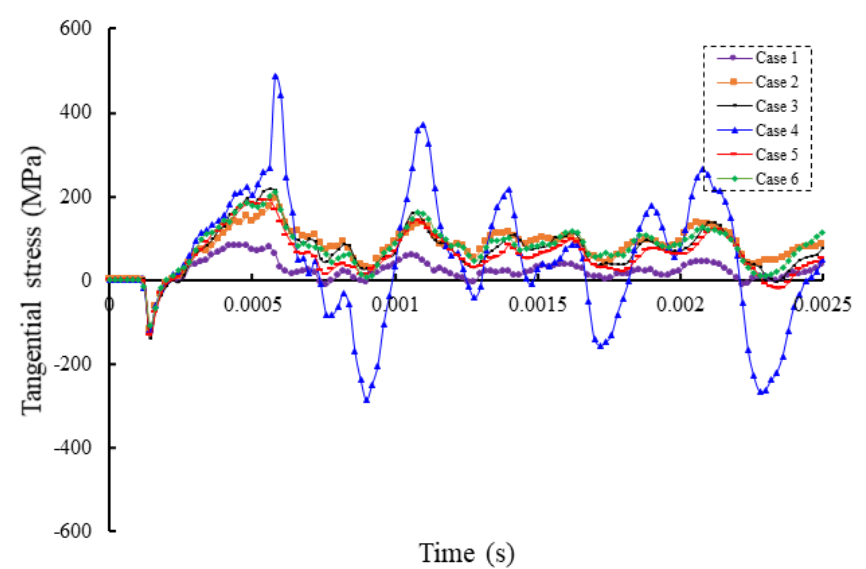

(a) \#1 monitoring point 


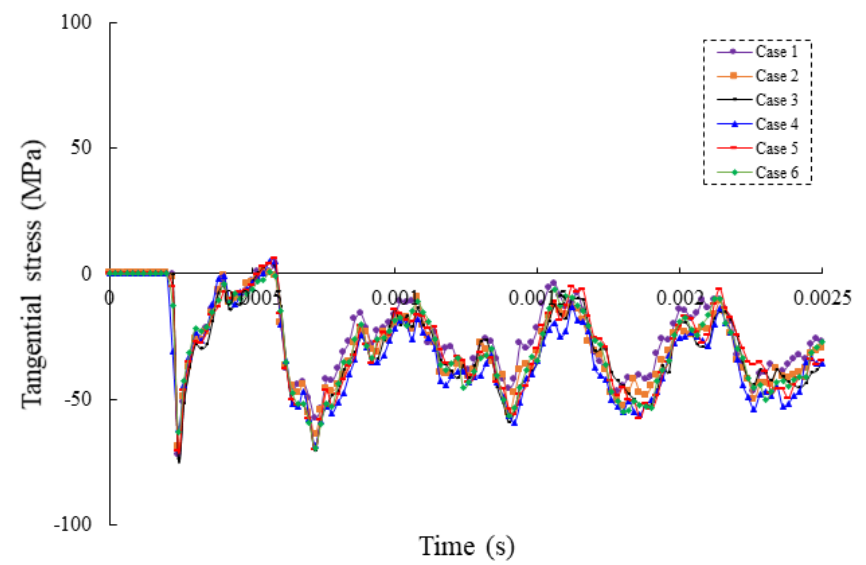

(b) \#2 monitoring point

Fig. 4 Tangential stress history curve for each case.

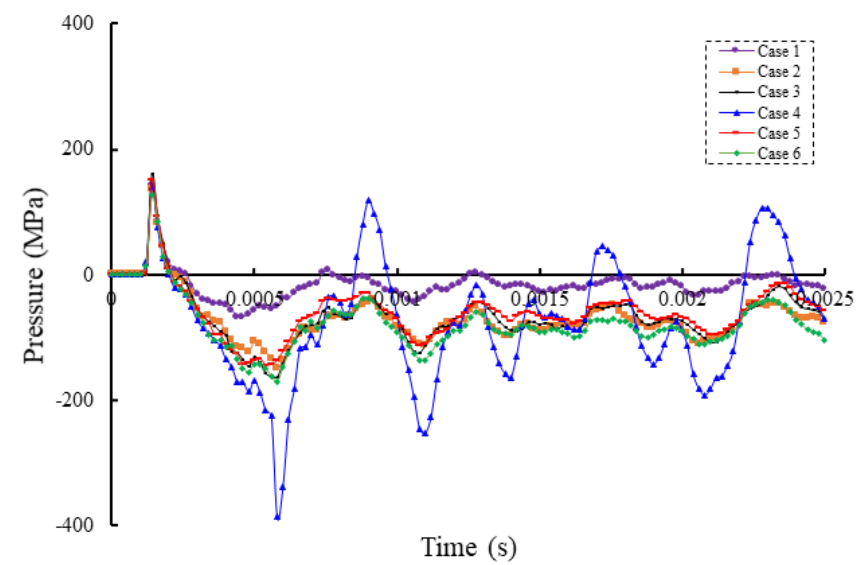

(a) \#1 monitoring point

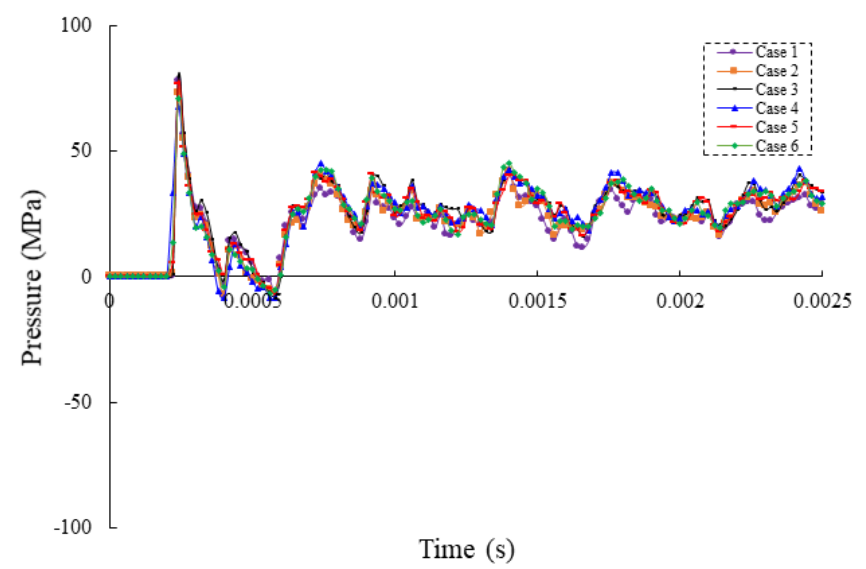

(b) \#2 monitoring point

Fig. 5 P-T history curve for each case. 


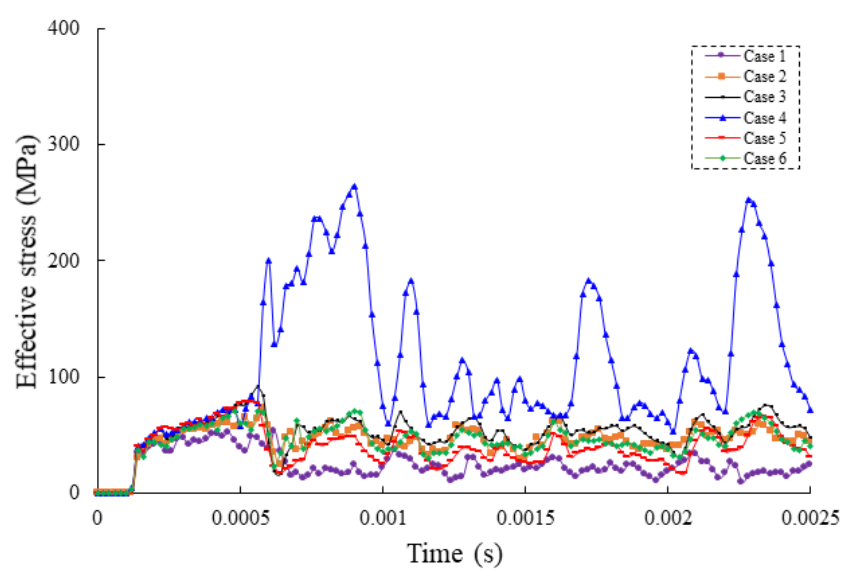

(a) \#1 monitoring point

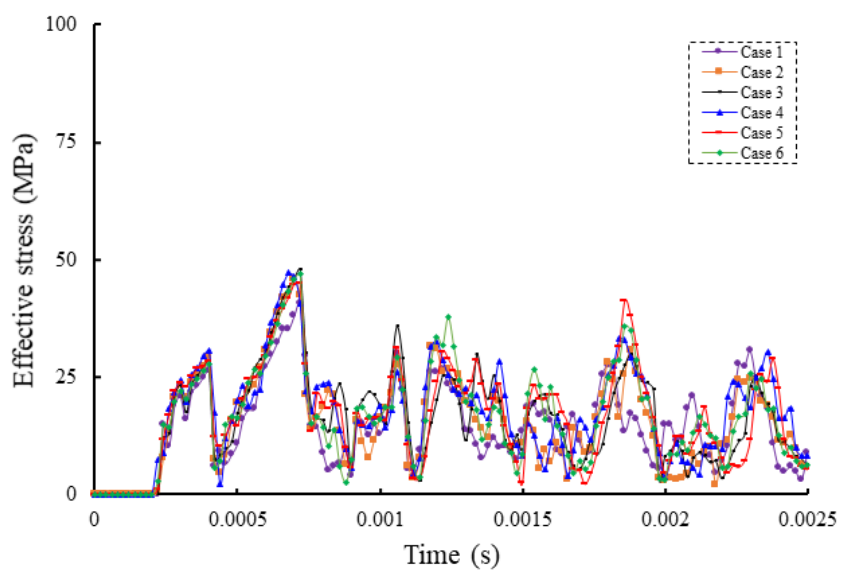

(b) \#2 monitoring point

Fig. 6 Effective stress history curve for each case

$$
\frac{\sin \beta}{\sin \alpha}=\frac{c_{\mathrm{s}}}{c_{\mathrm{p}}}=\sqrt{\frac{1-2 \mu_{\mathrm{r}}}{2\left(1-\mu_{\mathrm{r}}\right)}}
$$

where $\mu_{\mathrm{r}}$ is rock possion ratio.

Moreover, as the water jet slot can be considered as man-made fracture, the reflection and transmission of the stress wave will occur at the interface of the water jet slot. The interaction of the transmitted waves will occur near the water jet slot. Based on stress wave theory [17], the stress-strengthened region will form because the directions of the propagation of those transmitted waves are similar to each other, as shown in Fig. 7b, in which the lines marked as (1) and (2) stand for stress strengthening line. Therefore, assume that $\sigma_{\mathrm{nn}}$ and $\tau_{\mathrm{nn}}$ are the tresses on the interface of natural fracture respectively, they can be written as $[18,19]$

$$
\left\{\begin{array}{l}
\sigma_{\mathrm{nn}}=\rho_{\mathrm{r}} c_{\mathrm{p}} \cos 2 \beta\left(v_{\mathrm{ip}}+v_{\mathrm{rp}}-v_{\mathrm{tp}}\right)-\rho_{\mathrm{r}} c_{\mathrm{s}} \sin 2 \beta\left(v_{\mathrm{rs}}+v_{\mathrm{ts}}\right) \\
\tau_{\mathrm{mn}}=\rho_{\mathrm{r}} c_{\mathrm{p}} \sin 2 \beta \operatorname{tg} \beta \operatorname{ctg} \alpha\left(v_{\mathrm{ip}}-v_{\mathrm{rp}}-v_{\mathrm{tp}}\right)-\rho_{\mathrm{r}} c_{\mathrm{s}} \cos 2 \beta\left(v_{\mathrm{rs}}-v_{\mathrm{ts}}\right)
\end{array}\right.
$$

Combine formula (8) and (9) with formula (10), we can get

$\left\{\begin{array}{l}\sigma_{\mathrm{nn}}=\cos 2 \beta\left(\sigma_{\mathrm{ip}}+\sigma_{\mathrm{rp}}-\sigma_{\mathrm{tp}}\right)-\sin 2 \beta\left(\tau_{\mathrm{rs}}-\tau_{\mathrm{ts}}\right) \\ \tau_{\mathrm{nn}}=2(\sin \beta)^{2} \cot \alpha\left(\sigma_{\mathrm{ip}}-\sigma_{\mathrm{rp}}-\sigma_{\mathrm{tp}}\right)-\cos 2 \beta\left(v_{\mathrm{rs}}+v_{\mathrm{ts}}\right)\end{array}\right.$

where $\sigma_{\text {ip }}, \sigma_{\text {rp }}, \tau_{\text {rs }}, \sigma_{\text {tp }}$ and $\tau_{\text {ts }}$, are respectively, the stress value of incident $\mathrm{P}$-wave, reflected $\mathrm{P}$-wave, reflected S-wave, transmitted P-wave and transmitted $\mathrm{S}$-wave. Based on blasting stress wave theory [16], the relationship between each other can be written as: 


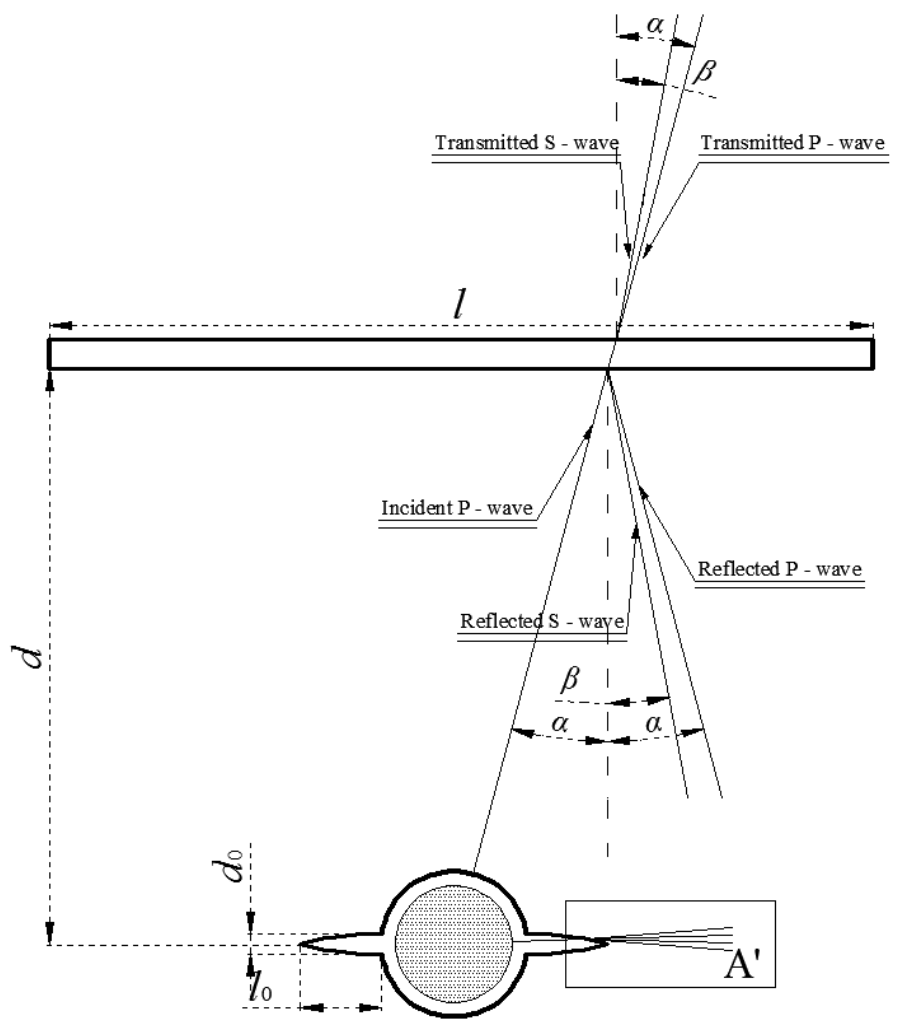

Fig. 7 Schematic diagram of blast wave propagation cross natural fracture and water jet slot.

$$
\begin{aligned}
& \sigma_{\text {rp }}=\sigma_{\text {ip }}\left(\frac{\frac{\left(1-2 \mu_{\mathrm{r}}\right) \sin 2 \alpha}{2\left(1-\mu_{\mathrm{r}}\right) \sin 2 \beta}-\tan \varphi}{\frac{\left(1-2 \mu_{\mathrm{r}}\right) \sin 2 \alpha}{2\left(1-\mu_{\mathrm{r}}\right) \cos 2 \beta}+\cot 2 \beta}\right) \\
& \tau_{\mathrm{rs}}=\sigma_{\text {ip }}\left(\frac{\tan \varphi-\frac{\left(1-2 \mu_{\mathrm{r}}\right) \sin 2 \alpha}{2\left(1-\mu_{\mathrm{r}}\right) \cos 2 \beta}}{1+\tan 2 \beta \frac{\left(1-2 \mu_{\mathrm{r}}\right) \sin 2 \alpha}{2\left(1-\mu_{\mathrm{r}}\right) \cos 2 \beta}}\right) \\
& \sigma_{\mathrm{tp}}=\sigma_{\mathrm{ip}}\left(\frac{\cot 2 \beta+\tan \varphi}{\cot 2 \beta+\frac{\left(1-2 \mu_{\mathrm{r}}\right) \sin 2 \alpha}{2\left(1-\mu_{\mathrm{r}}\right) \cos 2 \beta}}\right) \\
& \tau_{\mathrm{ts}}=\sigma_{\mathrm{ip}}\left(\frac{\tan \varphi-\frac{\left(1-2 \mu_{\mathrm{r}}\right) \cos 2 \alpha}{2\left(1-\mu_{\mathrm{r}}\right) \sin 2 \beta}}{1+\cot 2 \beta \frac{\left(1-2 \mu_{\mathrm{r}}\right) \cos 2 \alpha}{2\left(1-\mu_{\mathrm{r}}\right) \sin 2 \beta}}\right)
\end{aligned}
$$

where $\tan \varphi$ is friction coefficient of natural fracture. In addition, based on blasting theory $[14,16]$, when the natural fracture located in the crushed zone, $\sigma_{\text {ip }}$ can be calculated by formula (13):

$$
\sigma_{\text {ip }}=\left(\frac{2 \rho_{\mathrm{r}} c_{\mathrm{p}} P_{\mathrm{e}}}{\rho_{\mathrm{e}} D_{\mathrm{e}}+\rho_{\mathrm{r}} c_{\mathrm{p}}}\right)\left(\frac{r_{0} \cos a}{d}\right)^{\left(2-\left(\frac{\mu_{\mathrm{r}}}{1-\mu_{\mathrm{r}}}\right)\right)}
$$

where $\rho_{\mathrm{r}}, \rho_{\mathrm{a}}$ and $\rho_{\mathrm{e}}$ are, respectively, the density of rock, air and explosive., $c_{\mathrm{p}}$ is the P-wave propagation speeds in the intact rock, $P_{\mathrm{e}}$ is the detonation pressure of explosive, $r_{0}$ is the dimeter of blast hole, $d$ is the distance between natural fracture and blast hole, $\alpha$ is incident angle of blast shock wave, and $\mu_{\mathrm{r}}$ is rock possion ratio.

\subsection{Criteria for Crack Propagation under Blast Loading}

When an explosive blast occurs, the explosion shock wave acts on the blast hole wall and forms micro-fractures, and the crack then propagates under the detonation gas quasi-static effect [14]. Meanwhile, due to the dynamic character of the rock, the rock located in the near-blasting field can be considered 
fluid because the energy of the initial shock wave is much greater than the compressive strength of the rock, able to bear pressure rather than tensile force. Therefore, based on the maximum normal stress criterion, the failure criterion of the rock located in the blasting field under the shock wave loading can be written as formula (14).

$$
\left\{\begin{array}{l}
\left(\frac{2 \rho_{\mathrm{r}} c_{\mathrm{p}} P_{\mathrm{e}}}{\rho_{\mathrm{e}} D_{\mathrm{e}}+\rho_{\mathrm{r}} c_{\mathrm{p}}}\right)\left(\frac{r_{0}}{r_{\mathrm{b}}}\right)^{\left(2+\left(\frac{\mu_{\mathrm{r}}}{1-\mu_{\mathrm{r}}}\right)\right)} \geq \sigma_{\mathrm{p}} \\
\left(\frac{2 \rho_{\mathrm{r}} c_{\mathrm{p}} P_{\mathrm{e}}}{\rho_{\mathrm{e}} D_{\mathrm{e}}+\rho_{\mathrm{r}} c_{\mathrm{p}}}\right) \varepsilon \geq \sigma_{\mathrm{p}}
\end{array}\right.
$$

where $r_{\mathrm{b}}$ is the distance from blast hole, $\sigma_{\mathrm{p}}$ is the dynamic compressive strength of the rock, and $\varepsilon$ is the stress attenuation function of the shock wave during propagation in air.

Meanwhile, because the natural fracture can be considered as a free surface during blasting, the tension wave will form when the shock compressional wave arrives at the natural fracture $[14,20]$. As the strength of the extension is considerably smaller than the compressive strength of the rock, the rock will fail under the action of the tension wave based on the maximum tensile stress criterion, when the $\alpha=90^{\circ}$, the tension reached stress its maximum value, and the rock failure criterion can be written as formula (15).

$$
\left(\frac{4 \rho_{\mathrm{r}} c_{\mathrm{p}} P_{\mathrm{e}}}{\rho_{\mathrm{e}} D_{\mathrm{e}}+\rho_{\mathrm{r}} c_{\mathrm{p}}}\right)\left(\frac{r_{0}}{d}\right)^{\left(2+\left(\frac{\mu_{\mathrm{r}}}{1-\mu_{\mathrm{r}}}\right)\right)} \geq \sigma_{\mathrm{c}}
$$

where $\sigma_{\mathrm{c}}$ is the dynamic tensile strength of the rock.

In the similar way, when the natural fracture located in the reputed zone, the rock failure criterion can be written as formula (16).

$$
\left(\frac{4 \rho_{\mathrm{r}} c_{\mathrm{p}} P_{\mathrm{e}}}{\rho_{\mathrm{e}} D_{\mathrm{e}}+\rho_{\mathrm{r}} c_{\mathrm{p}}}\right)\left(\frac{r_{0}}{d}\right)^{\left(2-\left(\frac{\mu_{\mathrm{r}}}{1-\mu_{\mathrm{r}}}\right)\right)} \geq \sigma_{\mathrm{c}}
$$

After the effect of the shock wave, the detonation gas quasi-static effect becomes the main factor influencing crack propagation. In this paper, we focus on the blast-induced crack that propagates along the direction of the water jet slot, and to simplify analysis, the following hypotheses are made: I, The size of the rock is as large as possible; II, No other fractures or joints exist in the rock except the natural fracture and the water jet slot.

Based on fracture mechanics, the instability of the fracture propagation belongs to the category of a Model I crack problem, and according to the Irwin fracture mechanics theory [21-23], for a model I crack, the fracture will propagate when the stress intensity factor $K_{\mathrm{I}}$ reaches a critical value $K_{\mathrm{IC}}$. Otherwise, the fracture will stop, which can be written as follows:

$$
K_{\mathrm{I}}=K_{\text {ic }}
$$

where $K_{\mathrm{I}}$ is the stress intensity factor of Mode I, and $K_{\mathrm{IC}}$ is the critical stress intensity factor (fracture toughness). $K_{\mathrm{I}}$ and $K_{\mathrm{IC}}$ are calculated as follows:

$$
\left\{\begin{array}{l}
K_{\mathrm{I}}=\sigma_{0} \sqrt{\pi d_{0}} \\
K_{\mathrm{ic}}=\sqrt{\frac{2 E \gamma}{\left(1-\mu_{\mathrm{r}}\right)^{2}}}
\end{array}\right.
$$

where $\sigma_{0}$ is the stress acting upon the fracture plane, $d_{\mathrm{b}}$ is the length of the blast-induced crack, $E_{\mathrm{r}}$ is the elastic modulus of the rock, $\gamma$ is the surface energy per unit area, and $\mu_{\mathrm{r}}$ is the Poisson ratio of the rock. For the problem discussed in this work, $K_{\mathrm{I}}$ in the tip of the water jet slot can be determined as:

$$
K_{\mathrm{I}}=P_{0} F \sqrt{\pi\left(l_{0}+r_{0}\right)}
$$

where $P_{0}$ is the quasi-static pressure of the explosion gas, $F$ is the correction factor for the stress intensity factor, which is a function of the blast hole radius and the length of the crack, $r_{0}$ is the radius of the blast hole, and $l_{0}$ is the length of the water jet slot.

Combining formulas (18) with (19), the quasi-static pressure of the explosion gas for the crack propagation along the direction of the water jet slot can be expressed as:

$$
P_{0}^{\prime}=\frac{1}{F} \sqrt{\frac{2 E \gamma}{\pi\left(l_{0}+r_{0}\right)\left(1-\mu_{\mathrm{r}}\right)^{2}}}
$$


where $P_{0}{ }^{\prime}$ is defined as the pressure that allows the blast-induced crack to propagate along the direction of the water jet slot.

\section{Conclusions}

(1) The influence on the guiding characteristics by the change of the size of water jet slot during the propagation of blast-induce crack has its limit. If the distance from blasthole exceeds the limit, the influence on the guiding characteristics by the change of the size of water jet slot will get smaller and smaller.

(2) When the width of water jet slot remains the same, the stress shows a monotonic increasing trend with the increase of the length of the water jet slot, and the stress reaches its maximum value when the length-width of water jet slot is $0.075 \mathrm{~m} \times 0.0070 \mathrm{~m}$.

(3) Based on stress wave theory and rock fracture theory, the influential mechanism for both the law of transmission of stress wave and of crack propagation by natural fracture and water jet slot were analyzed. The criteria for blast-induced crack propagation were established.

\section{Acknowledgements}

Financial support for this work was provided by Natural Science Foundation of Southwest University of Science and Technology (18zx7124).

\section{References}

[1] Hu, Y., Lu, W., Wu, X. et al. 2018. "Numerical and Experimental Investigation of Blasting Damage Control of a High Rock Slope in a Deep Valley.” Engineering Geology: 237.

[2] Chi, G., Fuerstenau, M. C., Bradt, R. C. et al. 1996. "Improved Comminution Efficiency through Controlled Blasting during Mining." International Journal of Mineral Processing 47 (1-2): 93-101.

[3] Luo, Y., and Shen, Z. 2006. "Study on Cumulalive Energy Effect in Directional Fracture Controlled Blasting in Rock." Engineering Science 33 (1): 79-94.

[4] Zhang, Z. C. 2013. "Control in Blasting Engineering." Chinese Journal of Underground Space and Engineering 9 (5): 1208-14.
[5] Liu, J., Liu, Z. G., Gao, K. et al. 2014. "Experimental Study and Application of Directional Focused Energy Blasting in Deep Boreholes." Chinese Journal of Rock Mechanics and Engineering 33 (12): 2490-6.

[6] Yang, R. S., Ding, C. X., Yang, L. Y. et al. 2017. "Experimental Study on Controlled Directional Fracture Blasting on PMMA Mediums with Flaws." Chinese Journal of Rock Mechanics and Engineering 36 (3): 690-6.

[7] Kang, Y., Wang, X. C., Yang, X. F. et al. 2012. "Numerical Simulation of Control Blasting with Borehole Protecting and Water Jet Slotting in Soft Rock Mass." Disaster Advances 5 (4): 933-8.

[8] Kang, Y., Zheng, D. D., Su, D. F. et al. 2015. "Model of Directional Shaped Blasting Assisted with Water Jet and Its Numerical Simulation." Journal of Vibration and Shock 34 (9): 182-8.

[9] Kim, J. G., and Song, J. J. 2015. “Abrasive Water Jet Cutting Methods for Reducing Blast-induced Ground Vibration in Tunnel Excavation." International Journal of Rock Mechanics and Mining Sciences 75: 147-58.

[10] Su, D. F., Kang, Y., Wang, X. C. et al. 2016. "Analysis and Numerical Simulation for Tunnelling Through Coal Seam Assisted by Water Jet." CMES-Computer Modeling in Engineering \& Science 111 (5): 375-93.

[11] Bai, J. Z. 2005. Basis Theoretical and Instance Analysis of LS-DYNA3D. Beijing: Science Press.

[12] Cho, S. H., Nakamura, Y., Mohanty, B. et al. 2008. "Numerical Study of Fracture Plane Control in Laboratory-scale Blasting." Engineering Fracture Mechanics 75 (13): 3966-84.

[13] LSTC. 2008. LS-DYNA Keyword User's Manual (Version 970). Livermore. CA: Livermore Software Technology Corporation.

[14] Dai, J. 2013. Dynamic Behaviors and Blasting Theory of Rock. Metallurgical Industry Press.

[15] Gong, W. J., Wang, J. M., and Gao, N. 2011. "Numerical Simulation for Abrasive Water Jet Machining Based on ALE Algorithm." International Journal of Advanced Manufacturing Technology 53: 247-53.

[16] Guo, X. B., and Zhang, J. C. 2007. Blasting Engineering. China Communication Press.

[17] Wang, L. L. 1985. Foundation of Stress Wave. National Defence Industry Press.

[18] Li, J. C., and Ma, G. W. 2010. "Analysis of Blast Wave Interaction with a Rock Joint." Rock Mechanics and Rock Engineering 43 (6): 777-87.

[19] Kostyuchenko, V. N., and Pavlov, D. V. 2002. "Deformation Characteristics of Layers between Blocks at Different Scale Levels." Physical Mesomechanics 5 (5): 23-42.

[20] Johansson, D., and Ouchterlony, F. 2013. "Shock Wave 
Interactions in Rock Blasting: The Use of Short Delays to Improve Fragmentation in Model-scale." Rock Mechanics and Rock Engineering 46 (1): 1-18.

[21] Dyskin, A. V., and Galybin, A. N. 2000. "Fracture Mechanism of Pre-split Blasting." Paper presented on 7th International Symposium on Structural Failure and
Plasticity, 235-40.

[22] Atkinson, B. K. 1987. Fracture Mechanics of Rock. Academic Press.

[23] Li, S. Y., He, T. M., and Yin, X. C. 2010. Introduction of Rock Fracture Mechanics. University of Science and Technology of China Press. 